\title{
LEVANTAMENTO E ANÁLISE DE VÍDEOS DE PREVENÇÃO E DETECÇÃo PRECOCE DOS CÂNCERES DE CABEÇA E PESCOÇO PARA EDUCAÇÃO DE FONOAUDIÓLOGOS
}

\section{RESOURCES AND ANALYSIS OF VIDEOS ABOUT EARLY DETECTION AND PREVENTIVE ACTIONS AGAINST HEAD AND NECK CANCER FOR EDUCATION OF SPEECH THERAPISTS}

\author{
Mariana Pinheiro Brendim ${ }^{1}$, Luiz Augusto Rezende ${ }^{2}$ \\ ${ }^{1,2}$ Programa de Pós-graduação Educação em Ciências e Saúde, NUTES/UFRJ.
}

\section{Resumo}

Este artigo apresenta levantamento e análises de vídeos relacionados à prevenção e detecção precoce do câncer de cabeça e pescoço. Como resultados, foram encontrados cerca de 32 vídeos relacionados à temática, dos quais oito foram analisados. As análises procuraram avaliar as características composicionais dos vídeos, a generalidade ou especificidade das abordagens e o público a que se destinam. Ao final, os vídeos foram categorizados (em informativos e motivacionais) e foram feitas considerações sobre as possibilidades e dificuldades de apropriação desses materiais na formação do fonoaudiólogo.

Palavras-chave: Fonoaudiologia; câncer de cabeça e pescoço; recurso audiovisual.

\begin{abstract}
This article presents a research and an analysis of educational videos about early detection and preventive actions against head and neck cancer. The results showed about 32 videos for early detection and preventive actions against head and neck cancer. In this sample, eight videos have been analyzed. This analysis evaluated the characteristics of the videos, the generality and specificity of approaches and the definition of their target-publics. Videos were classified in motivational videos and information videos. To conclude were made appointments about the possibilities and difficulties of appropriation of such materials by teachers or speech therapists.
\end{abstract}

Key-words: Speech therapy; head and neck cancer; audiovisual resources.

\section{Introdução}

Este artigo relata um levantamento de vídeos produzidos no Brasil que tratam de forma educativo-científica das temáticas "câncer de cabeça e pescoço" (CCP) e "prevenção e detecção precoce do câncer" (PDPC). Este levantamento foi realizado no âmbito de um projeto que pretende avaliar as contribuições do recurso audiovisual para a formação do 
fonoaudiólogo no que diz respeito, mais especificamente, à preparação deste profissional para colaborar na prevenção e detecção precoce do CCP. Como profissional de saúde, o fonoaudiólogo tem importância fundamental não só para desempenhar as medidas de controle destes tipos de câncer, contribuindo para as ações de prevenção primária e secundária da doença, mas também, por atuar diretamente com a região de cabeça e pescoço, para detectar precocemente sinais desta doença. Da mesma forma, o papel do fonoaudiólogo é estratégico para o esclarecimento da população quanto aos fatores de risco e de prevenção.

Verifica-se, no entanto, que a formação do fonoaudiólogo não tem destacado esse importante papel, nem preparado adequadamente este profissional para desempenhá-lo (KOWALSKI, 1996; SILVA, REZENDE et al., 1996; CARVALHO, 2002). O uso de recursos audiovisuais poderia contribuir para que o graduando de Fonoaudiologia reconheça seu papel, como futuro profissional, de educador em saúde. Este uso, no entanto, deve levar em conta as potencialidades e limites dos recursos audiovisuais disponíveis e, para isso, é fundamental identificar e analisar as características destes materiais. Foi com este objetivo que o levantamento aqui apresentado foi realizado. Assim, além da identificação de alguns dos materiais existentes nessa temática, o artigo apresenta também uma análise e categorização destes. Esta análise teve como objetivo principal apresentar o conteúdo dos vídeos e avaliar, sempre que possível, o potencial educativo (seja informativo, seja motivador) de tais materiais no que diz respeito ao aspecto formal (características composicionais dos vídeos), à generalidade ou especificidade das abordagens e ao(s) público(s) a que se destina(m). Em tese, os resultados de um levantamento como o realizado neste trabalho podem servir para detectar lacunas na produção audiovisual disponível e, desta forma, orientar a realização de novos recursos em temáticas e abordagens mais específicas. Indicamos ainda algumas considerações sobre as dificuldades metodológicas desse tipo de levantamento e sugerimos alguns conceitos para análise e categorização de recursos audiovisuais que podem ajudar pesquisadores, profissionais de saúde e professores na avaliação dos materiais de que pretendem fazer uso. 


\section{Procedimentos utilizados e resultados obtidos no levantamento de vídeos nas temáticas de câncer de cabeça e pescoço (CCP) e prevenção e detecção precoce do câncer (PDPC)}

O levantamento dos vídeos foi realizado por meio de buscas nos catálogos do Canal Saúde, da Vídeo Saúde Distribuidora, ambos ligados à Fiocruz, e do Núcleo de Tecnologia Educacional para a Saúde - NUTES/UFRJ (especializado em materiais instrucionais para cursos superiores na área da Saúde, tais como Medicina, Odontologia, Enfermagem). Foram ainda pesquisados os sites You Tube (www.youtube.com.br) e do Instituto

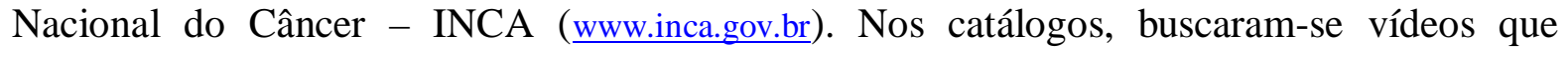
mostrassem clara relação com CCP e/ou com PDPC pela menção de um destes termos nos títulos e/ou nas sinopses encontradas. No caso do site You Tube, foram realizadas buscas com os termos "câncer", "câncer de cabeça e pescoço", "prevenção do câncer", "detecção precoce do câncer", "câncer de boca" e "câncer de laringe". O levantamento foi feito em "pesquisa avançada" com os seguintes parâmetros: "com todas as palavras", "todas as durações", "idioma português" e "categorias específicas" (ciência e tecnologia, educação, entretenimento, filmes e desenhos, pessoas e blogs, sem fins lucrativos e ativismo). Na página do INCA, foram buscados vídeos no link “multimídia”. Todos os levantamentos na internet foram realizados no dia 29 de setembro de 2008.

Entre as dificuldades metodológicas que encontramos neste levantamento, e que acreditamos serem comuns a outros levantamentos similares, estão a necessidade de utilizar parâmetros diferentes de acordo com as características de cada base e a exigüidade, e até mesmo inexatidão em alguns casos, das informações disponíveis nos catálogos. No caso das buscas em sites, essa situação se complica. A transitoriedade das páginas e endereços na internet cria problemas de acesso e localização dos vídeos. A pouca confiabilidade das informações dificulta a análise e a avaliação dos materiais disponíveis. Em geral, as buscas retornam um número muito grande de resultados, o que torna inviável a análise individual de cada item encontrado. Além disso, é freqüente que grande parte dos resultados encontrados não se refira aos parâmetros ou palavras-chave pesquisados. A dificuldade de estabelecer parâmetros precisos de busca também é grande. No You Tube, por exemplo, como não há controle sobre a postagem de vídeos (que é livre e individual), encontramos o mesmo vídeo com nomes diferentes. Além disso, há muitos erros de português no registro dos títulos e nos 
textos presentes nos vídeos.

No catálogo da Vídeo Saúde Distribuidora foram encontrados cinco vídeos, todos datados da década de 1990, e no do Canal Saúde apenas um, produzido em 2003. Já no catálogo do NUTES foram encontrados seis vídeos, dos quais apenas três relativos à temática específica em ponto, datados nas décadas de 1980 e 1990. No site do INCA, foram encontrados 12 vídeos, mas todos são centrados no combate ao fumo, já que fazem parte das campanhas publicitárias do Ministério da Saúde contra o tabagismo. No You Tube, quando realizado um levantamento espontâneo com a palavra "câncer", encontramos um total de 1050 vídeos. Esse resultado quantitativamente expressivo não refletia, no entanto, a temática da pesquisa, já que, numa revisão preliminar, muitos desses vídeos não se relacionavam a ela. Por este motivo, este parâmetro de busca ("câncer") foi desprezado para o site You Tube. Adotamos, portanto, outros parâmetros que se mostraram mais pertinentes aos objetivos do levantamento. Assim, para "câncer de boca", 17 vídeos foram encontrados, mas apenas 10 deles referem-se efetivamente ao câncer de boca. Na busca por "câncer de cabeça e pescoço", encontramos um único vídeo, sobre câncer de laringe. Com "câncer de laringe", foram obtidos 5 resultados, entre os quais 4 dizem respeito ao câncer de laringe propriamente dito. Com "prevenção do câncer”, foram 96 vídeos, sendo 15 deles referentes aos cânceres de cabeça e pescoço. Para “detecção precoce do câncer", foram encontrados apenas dois vídeos, ambos relacionados ao câncer de mama (cf. Quadro I).

Os vídeos encontrados no levantamento e considerados pertinentes à temática do câncer foram os seguintes. Catálogo do Canal Saúde: apenas um vídeo denominado "Câncer de boca". Vídeo Saúde Distribuidora: "Câncer, prevenir é viver", "Câncer de boca", "Prevenção ao câncer", "Segredo do câncer: prevenção e diagnóstico precoce". NUTES: "Câncer: fundamental é a vida" (versão consolidada) e "Câncer: fundamental é a vida", partes I e II. Site do INCA: apenas um tratava diretamente de câncer: "Euclides". Site You Tube (com parâmetros de busca foram um pouco diferentes, como explicado acima): em câncer de cabeça e pescoço foi encontrado o vídeo "A foto mais conhecida do Euclides". Em câncer de boca, os vídeos "Câncer de boca", "Cancer de boca", "Câncer de boca - dica do Dr. André Ricardo", "Cancêr bucal”, "Entrevista Fernando Xepa Scripilliti na Band - Câncer Bucal”, "Projeto Feliz Natal sem câncer bucal - Feliz Natal MT”, "HEG Entrevista Dr. Sassi - Prevenção de câncer bucal", "Cancer bucal”, "Pare de fumar! O 
cigarro é um veneno mortal. Imagens fortes" e "Não fume! O cigarro mata. Seu corpo é sua casa". Em câncer de laringe, "A foto mais conhecida do Euclides", "Pare de fumar! O cigarro é um veneno mortal. Imagens fortes", "Não fume! O cigarro mata. Seu corpo é sua casa" e "Câncer Laringe". Em prevenção do câncer, "Ana Paula Arósio, Campanha de prevenção ao câncer", "HEG Entrevista Dr. Sassi - Prevenção de câncer bucal”, "Câncer de boca", "Cancêr bucal”, "Projeto Feliz Natal sem câncer bucal - Feliz Natal MT", "Hospital do Câncer de Barretos", "Dr. Sérgio Vargas fala sobre câncer”, "A foto mais conhecida do Euclides", "Fundação Antonio Jorge Dino", "HEG 31 de maio - eventos do Dia Mundial sem Tabaco", "Alicc - Associação Limeirense de Combate ao Câncer", "HEG Entrevista Dr. Flavio Tomasich - Dia Mundial sem Tabaco", "HEG Entrevista Eduardo Senise - Parte I", "HEG 31 de maio - Evento nos Restaurantes" e "HEG Entrevista Eduardo Senise Parte 2". Os títulos "Euclides", "A foto mais conhecida do Euclides" e "Câncer de laringe" referem-se ao mesmo vídeo.

\section{Metodologia de Análise dos vídeos}

A metodologia de análise dos vídeos selecionados nesse levantamento se baseia nos princípios da análise fílmica francesa, tal como esta foi descrita por Vanoye e GoliotLété (1994). Segundo esses autores, analisar um filme implica "vê-lo, revê-lo e examiná-lo tecnicamente, para desmontá-lo e reconstruí-lo de acordo com uma ou várias opções a serem

QUADRO I - Resultados do levantamento

\begin{tabular}{|c|c|c|c|c|}
\hline \multicolumn{2}{|c|}{$\begin{array}{c}\text { Bases } \\
\text { Catálogos das Instituições }\end{array}$} & Vídeos encontrados & $\begin{array}{l}\text { Vídeos considerados } \\
\text { pertinentes à temática }\end{array}$ & Vídeos analisados \\
\hline & Canal Saúde & 1 & 1 & 1 \\
\hline \multicolumn{2}{|c|}{ Vídeo Saúde Distribuidora } & 5 & 4 & 3 \\
\hline \multicolumn{2}{|r|}{ NUTES } & 7 & 3 & 1 \\
\hline \multicolumn{2}{|r|}{ INCA } & 12 & 1 & 0 \\
\hline \multirow[b]{2}{*}{ You } & $\begin{array}{c}\text { câncer de cabeça e } \\
\text { pescoço }\end{array}$ & 1 & 1 & 0 \\
\hline & câncer de boca & 17 & 10 & 3 \\
\hline
\end{tabular}




\begin{tabular}{|c|c|c|c|c|}
\cline { 2 - 4 } Tube & câncer de laringe & 5 & 4 & 0 \\
\cline { 2 - 4 } & prevenção do câncer & 96 & 15 & 0 \\
\hline $\begin{array}{c}\text { detecção precoce do } \\
\text { câncer }\end{array}$ & 2 & 0 & 0 \\
\hline
\end{tabular}

precisadas". Analisar um filme é decompô-lo em seus elementos constitutivos, "é despedaçar, descosturar, desunir, extrair, separar, destacar e denominar materiais que não se percebem isoladamente a 'olho nu', pois se é tomado pela totalidade" (VANOYE e GOLIOT-LÉTÉ, 1994). Sendo assim, analisar um filme significa descrevê-lo e "desconstruilo" a fim de examinar cada um de seus fragmentos, considerando cada parte do todo. Como afirmam Aumont e Marie, "a intenção da análise é sempre a de chegar a uma explicação da obra analisada, ou seja, à compreensão de algumas de suas razões de ser" (AUMONT \& MARIE, 2003).

Por meio da análise fílmica é possível executar uma série de ações que podem esclarecer questões relacionadas ao caráter educativo dos audiovisuais, tais como: perceber a intenção e objetivos das obras; reconhecer a quem se dirige o material; de que linguagens se apropriam; quais conteúdos são abordados; que mensagens ou idéias são trabalhadas explícita ou implicitamente e quais estratégias discursivas são usadas. Por meio da "desconstrução" de seus objetos, a análise fílmica possibilita conhecer como uma determinada organização de recursos estéticos audiovisuais pode produzir determinados significados. A metodologia de análise fílmica de vertente francesa propõe primeiramente a identificação e a descrição dos recursos utilizados por um filme ou vídeo para posteriormente indicar que valores e sentidos estes recursos pretendem produzir junto ao espectador. Por meio da análise fílmica, também podemos avaliar como esses recursos são usados e segundo que intenções eles se orientam: o uso da voz-off de um locutor, por exemplo, pode ter o objetivo de conduzir o espectador à apreensão de saberes predeterminados, gerando um tipo de audiovisual intensamente "textualizado". Da mesma forma, poderíamos detectar na sua não utilização a tentativa de incentivar um espectador com olhar mais "livre" em sua relação com o "texto audiovisual". Em outro exemplo, o uso de muitos cortes pode ser analisado como um recurso para tornar um vídeo mais dinâmico, mas, ao mesmo tempo, pode produzir uma "fragmentação" que não permite ao espectador tempo necessário para assimilação e 
reflexão sobre o que ele vê e ouve. A análise fílmica também nos possibilita buscar uma avaliação sobre a adequação dos recursos usados e seu espectador pretendido.

Para análise dos vídeos levantados durante a pesquisa, partimos também das considerações de alguns trabalhos sobre o audiovisual educativo em ciências e saúde. Por meio destes textos, podemos perceber as várias funções, modalidades, estéticas e intenções assumidas pelo vídeo no contexto educativo, entre as quais desempenhar "papel de motivação, demonstração, organizador prévio e instrumento de apoio à exposição do professor" (CLEBSCH \& MORS, 2004; FERRÉS, 1998). Da mesma forma, os trabalhos de Moran (1994) e Arroio \& Giordan (2005) nos ajudam a reconhecer que os vídeos educativos podem se apresentar em diferentes modalidades. Esses autores contribuíram para esta análise com sugestões de categorização para as modalidades existentes de vídeos educativos. Para Moran (1994), os recursos audiovisuais podem ser utilizados como "motivação", como estímulos. Em outros casos, o autor afirma que esses recursos são essencialmente "informativos", cumprindo o papel de transmitir "conteúdos de ensino como informação" ao espectador, de forma organizada, clara e seqüenciada (MORAN, 1994: 23).

Para Arroio \& Giordan (2005), como já citado, além desta modalidade, encontrase o vídeo de motivação, cuja finalidade é, mais do que informar, motivar e sensibilizar o espectador. Esse tipo de vídeo trabalha o conteúdo de forma a promover a adesão a uma idéia, muitas vezes apelando para recursos de persuasão que jogam com a emoção do espectador. Em geral, esta modalidade é antagônica à idéia de que a informação deve ser essencialmente transmitida ao espectador, sem necessariamente o cuidado de despertar a observação, a reflexão e a motivação dos sujeitos. Assim, se os vídeos de informação privilegiam a exposição, geralmente textual, e a transmissão de informações ao espectador, os vídeos motivacionais priorizam a questão da motivação do espectador, visando sensibilizar e/ou persuadir este sujeito para o tema abordado, mais do que fornecer informações. Dessa forma, enquanto o vídeo motivacional tem a intenção de sensibilizar o espectador para o tema trabalhado, o vídeo de informação prioriza o conteúdo técnicocientífico. 


\section{Análise dos vídeos selecionados}

A seguir, apresentamos a análise de vídeos considerados pertinentes às temáticas da pesquisa. A seleção dos vídeos analisados obedeceu ao critério de relevância e pertinência conferido aos temas pesquisados. Foram analisados os vídeos encontrados que tratavam, de forma central, tanto de CCP, quanto de PDPC. Sendo assim, os vídeos que se relacionavam de alguma maneira ao tema, mas não o abordavam de forma específica, foram excluídos da análise, como foi o caso de vídeos pertencentes às campanhas anti-tabagistas, anti-etilistas e de propaganda de projetos e associações de combate à doença ou de apoio a pacientes. No caso dos vídeos da série "Câncer: fundamental é a vida", analisamos apenas a versão consolidada, já que esta é uma síntese das outras. A análise dos três vídeos dessa série seria redundante no que diz respeito aos objetivos deste trabalho. Foram privilegiados tanto os aspectos relativos aos recursos de expressão audiovisual, quanto aqueles relativos às temáticas em pauta, combinando, portanto, análise fílmica e análise de conteúdo.

O vídeo “Câncer de Boca” (2003), presente no catálogo do Canal Saúde/Fiocruz, consiste apenas em uma breve entrevista com um especialista, seguida de uma curta demonstração do auto-exame da boca. Como a maioria dos vídeos analisados, se enquadra em um formato telejornalístico, procurando informar brevemente, de forma superficial e geral, sobre alguns fatores de risco e sinais sugestivos da doença, assim como orientar sobre encaminhamento diante dos sinais suspeitos. Exibido no programa "Ligado em Saúde", do Canal Saúde, direciona-se ao grande público, e talvez por isso tenha um conteúdo marcadamente genérico e voltado às questões educativas e informativas consideradas necessárias à população. Este vídeo traz novas contribuições quanto aos fatores de risco da doença, em relação aos demais vídeos analisados - como a baixa ingestão de proteínas e vitaminas e a ênfase a determinadas infecções virais, como o papilomavírus e o HIV. Isto se dá, provavelmente, pelo fato de este vídeo ser mais recente e englobar novos conhecimentos, ou ainda pelo fato de refletir questões sócio-culturais atuais e preocupações dos meios de comunicação e da população relativas à maior divulgação de certas doenças como a AIDS ou HPV e hábitos saudáveis de alimentação.

Além disso, são abordados não só os fatores ambientais, como também a predisposição genética para o desenvolvimento da doença, na tentativa de esclarecer um 
questionamento muito comum da população: por que algumas pessoas que nunca fumaram ou beberam desenvolvem o câncer e outras que sempre fumaram e beberam não têm a doença? Nota-se que este vídeo preocupa-se em abordar as dúvidas da população a cerca do câncer. Em relação ao câncer de boca especificamente, ele enfatiza a falta de informação e divulgação sobre os sintomas e possíveis causas da doença, colocando-se, implicitamente, como fonte válida destas informações. É assim que é destacada a necessidade de educação das classes sociais menos favorecidas, que, segundo o vídeo, têm pouco acesso à informação e, por isso, se expõem aos fatores de risco. Toma-se como dado implícito a idéia de que os problemas relacionados à prevenção são resolvidos apenas com "mais informação". Há ainda, neste vídeo, uma ambigüidade de discurso, encontrada também em outros vídeos aqui analisados, no que diz respeito ao público-alvo: a informação relativa aos fatores de risco a que estão expostos o trabalhador rural parece descontextualizada, já que este tipo de informação interessaria mais ao profissional de saúde e às autoridades.

Outra questão, somente apontada por este vídeo, é a importância do auto-exame da boca para identificar lesões precursoras da doença. Apesar de o vídeo destacar quais são os sinais e sintomas que podem ser encontrados no auto-exame, ele não detalha como realizar este auto-exame, quais as estruturas que devem ser observadas - ele não cita, por exemplo, a investigação do soalho de boca, de palato duro e de palato mole. Além disso, a edição em planos curtos e rápidos não permite ao espectador uma maior chance de apropriação dos conhecimentos apresentados, de forma mais "dialógica" e privilegiando questionamentos e reflexões. As imagens acabam servindo meramente como ilustração de um discurso pronto, o que, no entanto, não auxilia a compreensão dos sintomas e da investigação da doença, dada a rapidez com que são apresentadas. O vídeo assume um discurso enfático de educação em prevenção, com o objetivo de alertar e se fazer conhecer à população os fatores de risco e medidas de incentivo à detecção precoce da doença. Como já apontado acima, pressupõe, portanto, que apenas a disponibilização da informação será suficiente para a mudança de comportamento em direção a atitudes mais preocupadas com os cuidados em prevenção do câncer ou na realização de auto-exames, colaborando, assim, para a sua detecção precoce. De certa maneira, o vídeo adota um discurso que coloca o indivíduo como principal responsável pela prevenção e também pelo adoecimento.

O vídeo “Câncer: Prevenir é Viver” (1992), encontrado no catálogo Vídeo 
Saúde/Fiocruz, se preocupa em definir de maneira simples o que é câncer, apontando como causas para o desenvolvimento da doença os fatores genéticos, sociais, culturais e geográficos. Além disso, são apresentadas estatísticas, suas relações com os sexos e hábitos de vida. Relaciona também os principais sintomas e "sinais de perigo" de diversos cânceres como endurecimento de nódulos da mama, ferida que não cicatriza, indigestão ou dificuldade de engolir, etc. Há uma demonstração passo a passo de como deve ser feito o exame clínico da mama, apresentando, inclusive, uma demonstração do aparelho de mamografia. Essa demonstração, além do vocabulário cientifico usado, nos sugere que este vídeo se dirige a estudantes da área da saúde, já que procura demonstrar procedimentos e técnicas específicos da área de conhecimento médico. No entanto, algumas informações parecem excessivamente superficiais para este público, tal como a definição de câncer, o que cria, como no vídeo analisado acima, uma ambigüidade em relação ao público a que se destina.

Outro aspecto observado é a questão da apresentação freqüente, nesse vídeo, de imagens de quadros com informações escritas e uma voz off lendo esses quadros. "Câncer: Prevenir é viver" enfatiza ainda a necessidade de "educação sanitária" e motivação da população como forma de prevenção ao câncer, já que, em certo trecho, menciona-se que o exame preventivo é acessível a todos, porém faltam motivação e educação sanitária para a população. Segundo Pimenta, Leandro \& Schall (2007), neste enfoque, dominante nos serviços e materiais educativos de saúde, ficam implícitos tanto um entendimento do audiovisual como um depositário de "informações e receitas do que se deve ou não fazer", quanto um modelo preventivo de abordagem, que focaliza somente fatores de riscos comportamentais e individuais, desconsiderando os fatores sociais e culturais, como se o indivíduo fosse uma tábula rasa. Além disso, quando aborda os fatores de risco, há um preconceito velado, pois o vídeo só considera sexualmente ativa a pessoa casada. Da mesma forma, sequer menciona o uso de camisinhas (masculina ou feminina) como método preventivo. Estes dados podem ser considerados indícios de desatualização do vídeo.

Analisando o vídeo “Prevenção ao Câncer” (1992), do catálogo da Vídeo Saúde/Fiocruz, notamos que se trata de um programa telejornalístico que procura dar ênfase à informação, utilizando o recurso amplamente reconhecido do repórter-interlocutor. Este vídeo é direcionado a qualquer público. A opção pela linguagem telejornalística, provavelmente considerada mais acessível pelos produtores, é um forte indício disso. 
Coloca-se claramente o objetivo de divulgar práticas de saúde e informar a população dos fatores de risco, melhorando os índices de prevenção do câncer. Apresenta os principais tipos de câncer que ocorrem na população brasileira, relata os principais sintomas do câncer bucal, como evitá-lo e preveni-lo. Este conteúdo informativo é predominantemente textual, ou seja, apresentado sob a forma da fala do especialista (o médico), solicitada e legitimada pela fala do repórter-apresentador. Desta forma, procura-se oficializar o que é dito, dando um sentido de verdade a essas informações: uma vez respaldadas pela voz de autoridade do especialista, elas ganhariam credibilidade junto aos espectadores (BERNARDET, 2003). O vídeo relaciona também algumas medidas de precaução para os trabalhadores rurais, como a utilização de chapéu, filtro solar e camisa de manga longa. Porém, não considera, em sua tentativa de resolução e/ou amenização do problema, as possibilidades reais de estes indivíduos terem acesso a tais produtos (principalmente o filtro solar), menosprezando assim o contexto social destes sujeitos. Percebe-se, nesse discurso, que a solução empregada pelos profissionais de saúde parece isentá-los da responsabilidade pelo descontrole da doença, já que supostamente oferecem a resolução da questão: a informação.

O vídeo "Segredo do Câncer: Prevenção e diagnóstico precoce”" (1992), do catálogo da Vídeo Saúde/Fiocruz, também adota o formato telejornalístico, com a presença de repórter-apresentador, voz-off e, mais uma vez, certa ambigüidade de "endereçamento", já que em muitos momentos as informações destinam-se ao público em geral, mas em outros, discute-se a postura do médico, parecendo, nestes casos, dirigir-se a esse grupo específico. O vídeo apresenta uma série de depoimentos curtos de pacientes e profissionais de saúde com o objetivo de motivar, enquanto a fala da repórter-apresentadora e as entrevistas aos médicos cumprem o papel de informar o espectador. As imagens, na maioria das vezes, exercem a função de ilustração da fala da repórter, apresentando o hospital, pacientes, aparelhos, cirurgias, exames e arquivos. Porém, contrariamente à maioria dos vídeos analisados, "Segredo do câncer: Prevenção e diagnóstico precoce" apresenta relatos e depoimentos otimistas de pacientes e especialistas incentivando a busca do paciente pelo tratamento o mais precocemente possível, enfatizando que a doença tem cura e tratamento: "Eu operei e está tudo bem", "O câncer tem saída... O câncer tem cura”, "A gente tem que procurar em primeiro lugar a vida”. Podemos considerar o uso destes depoimentos como um recurso de motivação do espectador, já que apela para o sentimento e a persuasão potencialmente 
presentes nas falas de indivíduos que passaram pela experiência do adoecimento (vozes de experiência). Trata-se, portanto, de um uso educativo potencial deste vídeo.

Percebe-se também a adoção de um discurso que acredita que a população, ainda nos dias de hoje, não conhece o prognóstico do câncer, encarando a doença como uma sentença de morte. Assim, o vídeo pretende desmistificar a doença, esclarecendo que ela tem cura, tratamento e prevenção. Por este motivo, o vídeo salienta a garantia dos médicos de que $80 \%$ das pessoas que morrem de câncer no Brasil poderiam se curar ou manter a doença sob controle se tivessem mais informação, maior acesso ao sistema de saúde e chegassem ao hospital oncológico logo que a doença surgisse. Além disso, é destacado que o câncer é a segunda causa de morte no Sul e Sudeste do Brasil, mas que os médicos acreditam que com mais informação e exames simples de prevenção, essa situação pode mudar. A prevenção e a detecção precoce do câncer são aspectos explorados pelo vídeo, informando ao espectador que a maioria dos tipos de câncer tem cura se forem identificados no início. Apesar de esses aspectos serem abordados pelo vídeo, em nenhum momento são apresentados os fatores de risco e/ou sinais e sintomas da doença.

Apesar de o vídeo destacar os avanços dos estudos sobre o câncer, da sofisticação dos equipamentos para diagnóstico e tratamento, do reconhecimento da importância de uma equipe de profissionais de saúde especializados para a adequação do tratamento, o vídeo relata que, ainda assim, apenas $10 \%$ das pessoas que chegam ao Hospital do Câncer, local onde foi realizada a produção do vídeo, conseguem se curar. Isso porque esses indivíduos chegam tarde demais aos hospitais especializados, devido a diversos fatores como falta de informação, dificuldade no acesso ao atendimento à saúde gratuito e falta de capacitação do profissional médico. Destaca-se, aqui, a consideração feita durante a apresentação do câncer de boca, que se enquadra, segundo o vídeo, entre os cânceres de mais fácil prevenção e destaca que "os homens são mais atingidos pelos (cânceres) de cabeça e pescoço, a boca especificamente". Observa-se, assim, que não se trata de um vídeo essencialmente "conteudista", mas de um vídeo que combina elementos informativos e motivacionais, procurando divulgar os avanços de detecção e tratamento da doença por meio da adoção de uma postura esperançosa e solidária.

O vídeo “Câncer: fundamental é a vida” (1988), do catálogo do NUTES, em contraposição à maioria dos vídeos analisados, considera uma visão mais integrada e 
humanista dos problemas da prevenção e detecção precoce do câncer, além de considerar um público-alvo mais específico - os estudantes de Medicina. Apesar disso, tem potencial para ser utilizado para os demais estudantes da área da saúde, mesmo não abordando situações cotidianas específicas destes profissionais. Este vídeo tem como objetivo sensibilizar os alunos, por meio de depoimentos de pacientes, quanto à importância da suspeita do câncer, além de motivar o aluno a repensar os procedimentos médicos e provocar uma visão crítica da prática médica no Brasil. O vídeo traz vários depoimentos de pacientes que vivenciam a angústia e os problemas enfrentados pelo câncer. Apresenta, ainda, a dramatização de uma equipe de produção de um vídeo educativo sobre o tema, relatando as dificuldades de produzir o material didático e discutindo os casos reais apresentados e a situação da doença no país. Em razão disso, trata-se de um vídeo auto-reflexivo que se estrutura como uma narrativa com personagens ficcionais que, ao mesmo tempo em que discute o câncer, discute também as dificuldades e objetivos de um vídeo educativo sobre essa temática. Esta narrativa é uma estratégia para contextualizar os depoimentos reais de pacientes com câncer e apresentar questões relacionadas ao ensino médico e à mobilização do profissional de saúde. $\mathrm{O}$ vídeo privilegia planos mais longos, que permitem a escuta dos depoimentos dos pacientes a um repórter-personagem, intercalados às cenas de discussão da equipe em um estúdio, e aspectos apontados pelos pacientes e problemáticas da doença. Pode-se assistir, por exemplo, o depoimento de um filho sobre a doença de sua mãe, que procura médicos e serviços de saúde, mas somente sete meses depois recebe o diagnóstico do câncer, quando já é tarde demais para tratá-la. Esse mesmo homem relata vivenciar novamente a mesma aflição na espera pelo atendimento na triagem do hospital, após ser encaminhado pelo dentista, devido à existência de manchas na cavidade bucal. $\mathrm{O}$ paciente destaca em seu depoimento o cuidado e as orientações fornecidas por esse profissional, porém assume uma postura pouco confiante nos serviços de saúde, associando a má qualidade de serviço à má qualidade de ensino.

Mas há também depoimentos que abordam a postura dos médicos; a necessidade desse profissional se perguntar qual é o seu papel social, já que neste papel está embutida a prática educativa que ele, querendo ou não, está cumprindo; o fato de muitos pacientes estarem muito mais preparados para receber o câncer do que os médicos estão para diagnosticar; a postura do profissional como detentor de poder, contribuindo para a falta de informação da população; o receio desses profissionais em suspeitar e falar com o paciente 
sobre o câncer; a necessidade dos acadêmicos de medicina compreenderem que o paciente se submete a qualquer tipo de exame quando se explica o porquê, o como e o que será feito; e a falta de confiança do médico no seu próprio saber, acreditando apenas na máquina. É também ressaltada a importância do preventivo, que segundo o vídeo, a longo prazo, é fundamental para a manutenção da saúde. Essas questões refletem uma perspectiva motivacional, uma vez que tratam de aspectos relacionados à prática médica e sua relação cotidiana com a prevenção e detecção do câncer.

O vídeo "Câncer fundamental é a vida" não tem como objetivo "ensinar" o aluno, cumprir a função de uma aula ou reforçar conteúdo, no sentido de que o vídeo viria a suprir uma deficiência de informação. Ao contrário, propõe-se a criar um espaço de questionamentos e reflexão quanto às problemáticas da prática médica nas ações de detecção precoce do câncer. Fica claro, assim, que, ao contrário dos outros vídeos, ele considera o contexto sócio-histórico-cultural do aluno-espectador como algo importante para a formulação da metodologia audiovisual empregada e não só a informação, ou a suposição de que o espectador a desconhece.

Endereçado à população em geral, o vídeo “Cancer de boca” (sic), apresentado no programa "RKC Notícias", é um vídeo de caráter informativo para o público em geral, em formato telejornalístico, que utiliza o recurso da voz off de uma repórter-apresentadora. As imagens, em planos curtos e rápidos, apresentadas pelo vídeo cumprem o papel de ilustrar a voz off. Ele informa que o câncer de boca atinge cada vez mais pessoas, sendo o sexto tipo de câncer mais comum no Brasil, e apresenta o estomatologista como o profissional que atende às doenças da boca, admitindo que esses profissionais são pouco conhecidos pela população. São mostradas imagens do "Programa Boca Maldita", em que os estomatologistas realizam exames nas ruas para identificar lesões que podem indicar a presença do câncer bucal. Por meio de depoimentos, enfatiza-se a importância da higiene oral e também do aprendizado do exame da boca como prevenção. O repórter apresenta o fumo e o álcool como as suas principais causas, ressaltando que $70 \%$ das pessoas que contraem a doença bebem ou fumam com regularidade e, ainda, que o hábito de fumar ou consumir álcool aumenta o risco em dez a vinte vezes. Porém, recomenda que mesmo quem nunca fumou ou bebeu também deve estar atento às lesões na boca que não regridem em até duas semanas. Próteses dentárias mal adaptadas também são apresentadas como fator de risco. Assim, 
observa-se que o vídeo traz, de forma superficial, informações sobre os fatores de risco e a importância da prevenção e do exame da boca para detecção precoce, considerando somente como sintoma da doença as lesões em cavidade oral. Dessa forma, "Cancer de boca" pode ser considerado, pelo menos em parte, deficiente quanto a seu propósito educativo, já que menciona a importância da realização do auto-exame, mas não o apresenta; valoriza a prevenção, mas apenas cita alguns poucos fatores de risco. Sem abordar tais temas, não se pode considerar que o vídeo cumpra o propósito de informar sobre detecção precoce.

O vídeo “Câncer de boca - dica do Dr. André Ricardo" é uma entrevista com o dentista, em um consultório. Voltada à população em geral, este fragmento tem por objetivo conscientizar o espectador a procurar o serviço de saúde mediante a presença de ferida na boca. $\mathrm{O}$ vídeo apresenta apenas duas cenas, uma em que um repórter apresenta rapidamente o especialista, e a outra, em que o especialista explana as questões relacionadas à doença à medida que aparecem imagens e figuras de livros sobre o câncer de boca. Nenhum outro recurso audiovisual, além da voz de autoridade do dentista e das imagens estáticas de livros, é usado. Segundo o vídeo, qualquer ferida tratada que não regrida em 21 dias é passível de avaliação de um profissional de saúde. Próteses mal-adaptadas, álcool, alimentos gordurosos, excesso de radiação solar, má higiene oral e fumo são causas da doença apontadas pelo especialista. Já em relação aos sinais e sintomas, o único sinal da doença apontado pelo especialista é a ferida em cavidade oral. O vídeo destaca ainda a questão do câncer de boca pertencer aos cinco tipos de câncer que mais matam no Brasil devido ao diagnóstico tardio. Percebe-se claramente nesse vídeo a adoção de um discurso puramente informativo que supõe que o indivíduo informado conscientiza-se da importância do abandono dos fatores de risco, assim como da importância da detecção precoce da doença, mesmo sem oferecer subsídios para o auto-exame e sinais e sintomas da doença.

“Cancêr Bucal” (sic), encontrado no You Tube, por sua vez, inclui-se na categoria dos vídeos pertencentes a campanhas de saúde pública, como peças de propaganda, já que é voltado ao público em geral, e objetiva persuadir o espectador por meio de frases de efeito e imagens chocantes sobre o câncer de boca. Os únicos fatores causais abordados pelo vídeo são o fumo e a bebida. Percebe-se a adoção de um discurso que pretende convencer o espectador a não fumar nem beber, a fim de não desenvolver a doença: "Você ama sua vida? Então pense...", "Você já imaginou como sofrem as pessoas que tem câncer (sic)?", "Talvez, 
os comerciais de bebidas, cigarros. Nunca tenham lhe abrido (sic) os olhos. Porém a realidade é outra", "Antes que aconteça com você previna-se”. Observa-se também que o vídeo exibe cartelas com diversos erros ortográficos e gramaticais da Língua Portuguesa, o que pode comprometer a intenção de "chocar" o espectador. Outro aspecto observado na análise desse vídeo é o fato deste não apresentar um caráter predominantemente informativo como a maioria dos outros vídeos. "Cancêr Bucal" é um vídeo de caráter de "motivação", mas se vale de uma estética de apelo de massa, de "espetacularização", morbidez e sensacionalismo, características estas diferentes das observadas nos demais vídeos de caráter motivacional. Percebe-se, pelos recursos usados neste vídeo, a intenção de provocar uma modificação do comportamento individual por meio de uma modalidade de motivação "de massa" que se vale de efeitos desgastados, concebendo os espectadores como um conjunto uniforme propenso a aceitar o que quer que lhe seja apresentado sem que ocorra nenhuma resistência ao que lhe é apresentado.

\section{Discussão}

Após a análise, os vídeos foram divididos em categorias: informativos ("Câncer de boca"/Canal Saúde, “Câncer, prevenir é viver", "Prevenção ao câncer”, “Câncer de boca"/You Tube e "Cancer de boca - dica do Dr. André Ricardo"), motivacionais (“Câncer: fundamental é a vida" e "Cancêr bucal”) ou "híbridos" ("Segredo do câncer: prevenção e diagnóstico precoce"). Os resultados confirmam a idéia de que, no vídeo de motivação, o apelo à emotividade e à afetividade do espectador é privilegiado em detrimento do conteúdo, e as informações tendem a ser mais contextualizadas, enquanto os vídeos de informação buscam promover uma mudança de atitude essencialmente por meio da transmissão de informações.

Por meio desta análise, percebe-se também que os vídeos classificados como de caráter informativo compartilham, na maioria das vezes, características comuns, enquanto os vídeos motivacionais apresentam-se de formas diferenciadas. Ou seja, nos vídeos informativos, observa-se a utilização do que poderíamos considerar um "formato telejornalístico", já que a necessidade de serem veiculados em tvs educativas, universitárias ou até mesmo canais abertos, em geral buscando um público amplo, condiciona a adoção deste formato em função de sua suposta maior abrangência e comunicabilidade. Este 
formato, no entanto, limita os recursos utilizados praticamente a entrevistas e narração-off de um repórter ou apresentador. Para Leandro (2001), esses recursos, típicos do telejornalismo, são simplesmente transportados aos vídeos educativos sem a devida contextualização dos fatores sociais e culturais implicados no tema abordado e à população a que se dirige. Desconsidera-se, assim, a importância do aspecto cultural do grupo a que o vídeo está dirigido (CLEBSCH \& MORS, 2004; PIMENTA, LEANDRO \& SCHALL, 2007).

Nos vídeos informativos, geralmente apela-se para o recurso da voz de autoridade, em que as informações e dados passados estariam implicitamente respaldados por serem apresentados por especialistas, cientistas, médicos. Esse recurso que se interpõe entre o espectador e a imagem não convida o espectador ao diálogo, tampouco permite que ele construa o seu próprio discurso (GRUZMAN, 2003). Além disso, pode-se notar, na maioria destes vídeos, uma certa ambigüidade no direcionamento para seu público-alvo, ou seja, muitas vezes eles se mostram "indecisos" em relação ao espectador visado, apresentando ora informações que se mostram adequadas ao público "leigo", ora informações mais especializadas, não definindo e considerando uma maior especificidade deste público. Este problema não parece ser exclusivo dos vídeos de câncer, já que também foi encontrado no levantamento de vídeos de leishmaniose realizado por Pimenta, Leandro \& Schall (2007). Percebe-se também a preocupação, nos vídeos dessa categoria, em transmitir informação aos espectadores, supondo a carência de conhecimentos por parte destes, limitando-se a uma abordagem freqüentemente bastante superficial. Como uma tendência geral, os vídeos de informação parecem sofrer mais rapidamente os problemas da desatualização do conteúdo do que os de motivação.

Os vídeos de motivação, apontados por diversos trabalhos como uma modalidade que possibilita trazer novas contribuições ao ambiente de ensino-aprendizagem (SIQUEIRA, 1998; MORAN, 1994), apesar de possuírem um mesmo propósito (sensibilizar o espectador), utilizam diferentes recursos e abordagens. Assim, determinados vídeos, como "Cancêr Bucal" (sic), utilizam-se de recursos sensacionalistas para supostamente "causar impacto", como imagens fortes e música ou apelo a uma pessoa pública, sem com isso suscitar momentos de reflexão ou questionamentos, em um formato idêntico ao dos filmes de propaganda. Esses vídeos poderiam ser categorizados como de "motivação de massa" por restringirem os aspectos motivacionais de que se utilizam a recursos insistentemente 
utilizados e consagrados pela grande mídia. Sem atentar para as diferenças sócio-culturais que podem existir entre os diversos espectadores que buscam atingir, estes vídeos pressupõem que tais recursos são mais legítimos em uma comunicação de massa porque supostamente produziriam os mesmos efeitos em todos os espectadores, independentemente das diferenças que existem entre eles. Já outros vídeos, também entendidos, pelo menos parcialmente, como de motivação, como "Segredo do câncer: prevenção e diagnóstico precoce" ou "Câncer: fundamental é a vida", adotam uma linguagem esperançosa e solidária com o doente, mesmo quando apresentados em formato telejornalístico, pois valorizam os depoimentos de pacientes (vozes de experiência) de forma a provocar questionamentos e reflexões. Neste sentido, as "vozes da experiência" nos vídeos de motivação servem a propósitos diferentes e mostram outros aspectos das questões e problemas apresentados por meio das "vozes de autoridade" dos vídeos de informação.

\section{Conclusões}

Um resultado importante do levantamento aqui realizado é que não foi encontrado nenhum material direcionado especificamente ao fonoaudiólogo, ou que tratasse a questão do CCP do ponto de vista fonoaudiológico ou da prática profissional do fonoaudiólogo, considerando o caráter estratégico do papel deste profissional, como apontado no início deste artigo. Apesar disso, como instrumentos educativos na formação do fonoaudiólogo, os vídeos analisados apresentam diferentes possibilidades. Primeiramente, ainda que os vídeos de caráter informativo possam ser usados para "passar conhecimento", essa estratégia pode não ser a mais adequada no que diz respeito ao uso do audiovisual para educação, já que outras tecnologias e recursos podem suprir essa função de maneira mais específica e atualizada, no caso da Fonoaudiologia. Isto acontece principalmente quando as informações passadas são eminentemente textuais, ou seja, não precisam de um suporte audiovisual, como a demonstração do auto-exame da boca, por exemplo, precisaria. Este procedimento, por sinal, foi encontrado em dois vídeos, mas sempre de maneira rápida e curta, textualmente e não visualmente orientado, sem desenvolver passo-a-passo a própria demonstração. Os vídeos motivacionais, por sua vez, têm um interesse maior, porque podem ser usados para discutir questões relacionadas aos saberes necessários à prática 
fonoaudiológica, como a importância da atuação do fonoaudiólogo na prevenção e detecção precoce do CCP. Valendo-se de recursos específicos de som e de imagem (como as entrevistas de pacientes), os vídeos motivacionais podem ser usados para discutir de forma mais corporificada questões como atitude e comprometimento profissional, valores morais, ética, linguagem e comportamento do paciente e do profissional de saúde.

De qualquer forma, por não tratarem da questão do ponto de vista fonoaudiológico, a utilização dos vídeos analisados acima em contextos educativos da graduação em Fonoaudiologia, ou mesmo na apropriação destes recursos pelo profissional fonoaudiólogo em práticas educativas, deve ser feita com todo cuidado. Deve-se adaptar e "traduzir" esses vídeos para o contexto e para o ponto de vista fonoaudiológico. No entanto, a necessidade de tais adaptações pode não ser evidente para os possíveis usuários dos vídeos, o que pode dificultar a apropriação destes recursos e reduzir o alcance da sua contribuição na formação profissional do fonoaudiólogo. Daí a necessidade de realizarem-se esforços para "recatalogar" e identificar os materiais audiovisuais educativos por meio de levantamentos que auxiliem o professor e o profissional de saúde na apropriação significativa deste tipo de recurso. Acreditamos, portanto, que o uso de audiovisuais nos mais diversos contextos educativos não deveria prescindir do levantamento prévio e da análise dos materiais disponíveis nas temáticas ou áreas de conhecimento que forem seu objeto de ensinoaprendizagem.

\section{Referências Bibliográficas}

ARROIO, Arroio \& GIORDAN, Marcelo. A Utilização do Vídeo Educativo como Possibilidade de Domínio da Linguagem Audiovisual pelo Professor de Ciências. Atas do V ENPEC, $n^{\circ}$ 5, novembro, 2005.

AUMONT, Jacques \& MARIE, Michel. Dicionário Teórico e Crítico de Cinema.

Campinas: Papirus, 2003.

BERNARDET, Jean-Claude. Cineastas e Imagens do Povo. São Paulo: Cia das Letras, 2003.

CARVALHO, André. Câncer da cavidade oral em países desenvolvidos e em desenvolvimento: estudo comparativo entre dois centros especializados. Tese (Doutorado) - Universidade de São Paulo, São Paulo, 2002.

CLEBSCH, Angelisa; MORS, Paulo. Explorando recursos simples de informática e audiovisuais: uma experiência no ensino de fluidos. Rev. Bras. Ens. Fis., 26, 4, (323-333), agosto, 2004.

FERRÉS, Joan. Pedagogia dos meios audiovisuais e pedagogia com os meios audiovisuais. In: Sancho, Juana. Para uma tecnologia educacional. Porto Alegre: ArtMed, 1998, (127- 
155).

GRUZMAN, Eduardo. Representações dos insetos através da imagem: uma investigação teórico-prática para a realização de um vídeo educativo em eco-entomologia. Dissertação (Mestrado) - UFRJ, Rio de Janeiro, 2003.

KOWALSKI, Ivonete. A parceria de professores e profissionais da saúde na prevenção do câncer: possibilidades e dificuldades. Dissertação (Mestrado) - PUC, São Paulo, 1996. LEANDRO, Anita. Da imagem pedagógica à pedagogia da imagem. Comunicação e Educação, 7, (29-36), 2001.

MORAN, Jose. Educação, comunicação e meios de comunicação. In: TRUFFI, Ymair; FRANCO, Luiz (org.). Multimeios aplicados à educação: uma leitura crítica. São Paulo: Série Idéias, 1994 (9-20).

PIMENTA, Denise; LEANDRO, Anita; SCHALL, Virgínia. A estética do grotesco e a produção audiovisual para a educação em saúde: segregação ou empatia? O caso das leishmanioses no Brasil. Cad. Saúde Pública, 23, 5 (1161-1171), maio, 2007. SILVA, A.; REZENDE, M. et al. Câncer de boca - manual de detecção de lesões suspeitas. Rio de Janeiro: INCA/PRO-ONCO, 1996.

SIQUEIRA, Vera. O vídeo educativo produzido pelo Núcleo de Tecnologia Educacional para a Saúde/UFRJ: Uma visão crítica. Revista Brasileira de Educação Médica, 22, (7782), set/dez,1998.

VANOYE, Francis; GOLIOT-LÉTÉ, Anne. Ensaio sobre a análise fílmica. Campinas: Papirus, 1994.

\section{Vídeos Analisados}

CANAL SAÚDE \& COOPAS MULTIMAGENS. Câncer de boca. Rio de Janeiro, 2003. FUNDAÇÃO JOAQUIM NABUCO. Câncer, prevenir é viver. Recife, 1992. MANDURI PRODUÇÕES. Segredo do câncer: prevenção e diagnóstico precoce. São Paulo, 1992.

NUTES-UFRJ. Câncer: fundamental é a vida (vesão consolidada). Rio de Janeiro, 1988. SECRETARIA ESTADUAL DE SAÚDE MS. Prevenção ao câncer. Campo Grande, 1992.

YOU TUBE. Câncer de boca. Sl, sd. Acessado em 29 de setembro de 2008. <http://br.youtube.com/watch?v=xhi85hqZkwQ\&mode=related\&search=>.

Câncer de boca - dica do Dr. André Ricardo. Sl, sd. Acessado em 29 de setembro de 2008. 〈http://br.youtube.com/watch?v=4PIxeJ0YXkA〉.

Cancêr bucal. S1, sd. Acessado em 29 de setembro de 2008.

<http://br.youtube.com/watch?v=iv0pJz-7U-A>. 